\title{
Pharmacy-Based Point-of-Care Testing: How a "Standard of Care" Approach Can Facilitate Sustainability
}

\author{
Alex J. Adams, PharmD, MPH${ }^{1}$; Donald G. Klepser, PhD, MBA ${ }^{2}$; Michael E. Klepser, PharmD³; Jennifer L. Adams, PharmD, EdD ${ }^{4}$ \\ ${ }^{1}$ Idaho Division of Financial Management; ${ }^{2}$ University of Nebraska Medical Center, College of Pharmacy; \\ ${ }^{3}$ Pharmacy Practice, Ferris State University, College of Pharmacy; ${ }^{4}$ Idaho State University, College of Pharmacy
}

\begin{abstract}
COVID-19 spurred rapid expansion of pharmacy-based point-of-care testing (POCT). This growth was aided, in part, by federal guidance that removed state-level regulatory uncertainty surrounding the ability of pharmacists to administer, interpret, and act on the results of tests. Surveys suggest there is considerable confusion about the legality of these services by state regulators. To ensure the sustainability of POCT services over time, states should consider adopting a standard of care approach to regulation, allowing a flexible framework for practice innovation and expansion over time.
\end{abstract}

\section{Background}

While pharmacists have provided point-of-care testing (POCT) services for years, uptake of the service increased considerably during the 2019 coronavirus (COVID-19) pandemic. ${ }^{1-3}$ Heightened demand for testing compelled the need for more access points throughout the United States. The number of pharmacies providing testing services grew by $45 \%$ between 2015 and November 2020, with the largest gains occurring in the last year amid the pandemic. ${ }^{4}$

Sustaining the growth of pharmacy testing services will require concentrated efforts, including the development of a more supportive regulatory environment. State-level regulatory impediments have been known to limit uptake of POCT services at pharmacies. $^{5}$ For example, a minority of states require pharmacies to have a laboratory director with certain credentials in order to provide testing. A few states similarly limit the tests that pharmacists may administer to only a small subset of those available. ${ }^{6}$ As a result, the percentage of pharmacies with testing services ranges from $2.92 \%$ to $56.52 \%$ across states. ${ }^{4}$

There is also considerable confusion by state regulatory agencies about what is necessary for pharmacists to provide testing services. ${ }^{7}$ This is because the legal authority for laboratory testing is often spread across multiple state laws, not just the state's pharmacy practice act. ${ }^{8}$ While federal action during the pandemic temporarily allowed pharmacists to perform POCT services in all jurisdictions, there is a need for more permanent solutions in order for there to be certainty that these services can continue over time. ${ }^{9}$

This paper addresses the requisite regulatory allowances for pharmacy-based POCT services to work in practice, and it makes a recommendation that states pursue a "standard of care" regulatory approach to facilitate continued growth.

Corresponding author: Alex J. Adams, PharmD, MPH Idaho Division of Financial Management, Boise, ID Email: alexadamsrph@gmail.com

\section{The Leaky Regulatory Bucket}

To meaningfully provide POCT services, pharmacists need to have the legal authority to 1) administer tests; 2) interpret the results of tests; and 3 ) act on the results of tests.

In a survey of boards of pharmacy (inclusive of all states, the District of Columbia, Guam, and Puerto Rico), 37 boards (70\%) reported affirmatively that pharmacists may administer tests, 31 boards (58\%) reported pharmacists may interpret the results of those tests, and only 24 boards (45\%) reported that pharmacists may act on the results of tests by prescribing a necessary medication. ${ }^{10}$

This creates a "leaky bucket" in which pharmacists may not be able to perform all activities necessary for meaningful POCT services. For example, there is limited value to a pharmacist providing a test to a patient if the pharmacist may not simultaneously interpret the result of the test and advise the patient of such.

Similarly, if acting on the result of the test (however simple the action may be) requires a referral to another venue of care, this significantly reduces the value proposition of offering testing in a pharmacy setting. Indeed, a considerable part of the value in pharmacy POCT is convenience, driven both by geographic access and hours of operation that extend beyond more traditional care settings. ${ }^{11}$

\section{Is Express Permission Needed to Provide POCT Services?}

While the aforementioned survey results suggest a need to prioritize legislation to broaden pharmacist authority, there is reason to believe the results may be driven, in part, by confusion on behalf of the regulatory boards. Education efforts directed at regulatory agencies may be as important a tool in enabling POCT as updating laws.

In November 2020, there were 3,827 pharmacies holding a certificate of waiver under the Clinical Laboratory Improvement Amendments of 1988 (CLIA) in states that responded to the survey in a manner that indicated pharmacists could not administer tests in those states. ${ }^{4}$ This is not an insignificant 
number of pharmacies, as it represents $24 \%$ of the total number performing POCT services in the United States. This means 3,827 pharmacies held the necessary credentials to administer tests in states that said such administration was impermissible.

The discordance in survey response is not attributed to the temporary federal allowances alone, as a similar survey in 2015 found a gap between what pharmacies were doing with POCT versus what regulatory boards reported as being legally permissible. ${ }^{7}$ Given the conservative nature of most pharmacists, it is highly improbable that CLIA-waived tests are being administered in states illegally; rather, it is more likely than not that the regulatory boards have incorrectly reported that administration of tests as prohibited because there is not an express allowance in the state's pharmacy law, even if it is not expressly prohibited by the state.

Similarly, we find it highly unlikely that many state laws explicitly prohibit a pharmacist who administers a test from simultaneously interpreting the result of that test. Nearly all pharmacies (99.85\%) offering POCT limit their services to tests waived under CLIA. ${ }^{12}$ CLIA-waived tests are, by definition, "simple" and carry a "low risk of error." ${ }^{13}$ Some CLIA-waived tests are approved for home use, in which an untrained lay person can both administer the test and interpret their own result. It defies logic to think that any state law would allow untrained lay persons to interpret the result of their selfadministered test but prohibit a trained pharmacist from doing the same in conjunction with the patient.

Lastly, acting on the result of a test may involve prescribing a medication or adjusting the dose of a patient's current prescription. For example, a pharmacist may prescribe antimicrobials based on the result of a POCT for influenza or Group A streptococcus, or add-on therapy to patient with diabetes who is not achieving their clinical goals relative to tests. ${ }^{14}$ The survey result likely underrepresents the extent to which pharmacists can legally act on the results of tests. While only two states (Colorado and Idaho) allow pharmacists to independently prescribe for any condition diagnosable by a CLIA-waived test and any minor ailment, prescribing more commonly occurs under a Collaborative Practice Agreement (CPA). ${ }^{15-16}$ In a CPA, a physician delegates the ability to prescribe to pharmacists under a formal written agreement. ${ }^{17}$

At least 48 states allow pharmacists to participate in a CPA, and thus they offer a basic framework for pharmacists to act on the results of tests. ${ }^{18}$ This is double the number of states responding affirmatively to the survey. Not all 48 of these state CPA laws are optimal, however. Some of these states limit pharmacist authority to post-diagnostic care which could prohibit acting on the results of diagnostic CLIA-waived tests. ${ }^{5}$ Others may limit the practicality of acting on the results of tests by limiting CPA services to rigidly defined patient populations. ${ }^{19}$ So, while regulator education may be beneficial here as well, changes to law are most likely necessary in some states in order to unleash the full potential of pharmacists to act on the results of tests.

\section{A Path Forward}

Given the demonstrable confusion from regulatory agencies over the legal status of pharmacy POCT services, it is perhaps not surprising that fewer than three in ten community pharmacies nationwide are providing the service. ${ }^{4}$

This regulatory uncertainty is likely a byproduct of pharmacy being the most regulated of the health professions. ${ }^{20-21}$ States vary in regulatory volume from 38 to 253 pages of pharmacy regulations, far exceeding both the medical and nursing professions. ${ }^{22}$ Some regulators have interpreted this regulatory morass to mean that if a service is not explicitly allowed in law, it is therefore prohibited. As demonstrated by 3,827 pharmacies administering POCT services in states that said it was impermissible, it is clear that many pharmacies have found a legal path forward even in the absence of express permission.

Thus, while many could contend that it would be ideal to have a clear law directly stating that pharmacists may administer, interpret, and act on the result of tests, this need not be the case, and may not be the ideal. The need for express permission is often limiting, especially as certain variables (such as education, technology, and practice environments) change over time necessitating changes in the legal permissions. What if every state had had to rewrite their regulations to allow pharmacists to expressly test for COVID-19?

Further, regulatory uncertainty is not limited to POCT. Eid and colleagues recently reported on state laws enabling pharmacy technicians to administer vaccines and reported on states that did not expressly prohibit the act, and found a similar discordance between the plain text of state laws and the results reported by the regulatory agencies surveyed. ${ }^{23}$ Thus, the need to itemize permission for each and every activity to remove uncertainty could become overwhelming to the profession and regulatory agencies in the years ahead.

A more ideal regulatory framework for POCT and other services is what some have termed "permissionless innovation." ${ }^{24}$ The medical profession has embraced this regulatory model, governing not by express permission, rather governing based on a "standard of care." The term standard of care refers to "that which a minimally competent physician in the same field would do under similar circumstances." 25 There are not prescriptive regulations outlining what services physicians may perform, they are instead expected to use their clinical judgment and may be held accountable for deviations from the standard of care.

A standard of care model is flexible enough to evolve as practice and technology change. It provides a simpler framework for delivering care - including POCT. Any service that a competent 
pharmacist would do in same or similar circumstances is interpreted to be allowed.

In providing any service, it would compel the pharmacist and their employer to consider their education, training, and experience, and have suitable protocols in place to ensure patient safety. Thus, a standard of care model would allow a pharmacist to administer, interpret, and act on the result of a test, if the pharmacist has the requisite clinical ability to do so. It also provides a broader framework for pharmacists to fully engage as part of the healthcare team as public health needs change over time, while maintaining the accountability to pursue disciplinary action against bad actors.

\section{Conclusion}

COVID-19 spurred rapid expansion of pharmacy-based POCT. This growth was aided, in part, by federal guidance that removed state-level regulatory uncertainty surrounding the ability of pharmacists to administer, interpret, and act on the results of tests. To ensure the sustainability of POCT services over time, states should consider adopting a standard of care approach to regulation, allowing a flexible framework for practice innovation and expansion over time.

\section{References}

1. Rodis JL, Thomas RA. Stepwise approach to developing point-of-care testing services in the community/ambulatory pharmacy setting. J Am Pharmacists Assoc. 2006;46(5):594-604.

2. Broughel J, Yatsyshina Y. Relax Pharmacy Regulations to help with COVID-19 Testing and Treatment. Mercatus Center Policy Briefs. March 27, 2020. Available from: https://www.mercatus.org/system/files/broughel_an d_yatsyshina_-_policy_brief_-_covid_series__what_covid19_means_for_the_practice_of_pharmacy__v1_1.pdf (Accessed July 10, 2021)

3. Patel S, Ogurchak J. Expanding the Role of Pharmacists in Wake of COVID-19. Pharmacy Times. June 29, 2020. Available from: https://www.pharmacytimes.com/news/expandingthe-role-of-pharmacists-in-wake-of-covid-19 (Accessed July 10, 2021)

4. Klepser NS, Klepser DG, Adams JL, et al. Impact of COVID-19 on prevalence of community pharmacies as CLIA-Waived facilities. Res Social Adm Pharm. 2020 December 15. Doi: 10.1016/j.sapharm.2020.12.003

5. Adams AJ, Weaver KK. Pharmacists' Patient Care Process: State "Scope of Practice" Priorities for Action. Ann Pharmacother. 2021;55(4):549-555. https://doi.org/10.1177/1060028020950193
6. Adams AJ, Weaver KK. Pharmacists' Patient Care Process: A State "Scope of Practice" Perspective. Innovations in Pharmacy. 2019;10(2). DOI: https://doi.org/10.24926/iip.v10i2.1389

7. Klepser ME, Adams AJ, Klepser DG. Clinical service implementation in the face of initial regulatory uncertainty. J Am Pharm Assoc. 56(2016):492.

8. Adams AJ, Dering-Anderson A, Klepser ME, Klepser D. The Roles of Pharmacy Schools in Bridging the Gap Between Law and Practice. American Journal of Pharmaceutical Education. 2018;82(4):6577. https://doi.org/10.5688/ajpe6577

9. U.S. Department of Health and Human Services (HHS). HHS Statements on Authorizing Licensed Pharmacists to Order and Administer COVID-19 Tests. Available from:

https://www.hhs.gov/about/news/2020/04/08/hhsstatements-on-authorizing-licensed-pharmacists-toorder-and-administer-covid-19-tests.html. (Accessed July 10, 2021)

10. National Association of Boards of Pharmacy. 2021 Survey of Pharmacy Law. January 2018. Chicago, IL.

11. Roberts GE, Rubin SE, Smith JK, et al. Public Health Perceptions of Community Pharmacy Partnership Opportunities. J Public Health Management and Practice. 2015;12(4):423-415. Doi: 10.1097/PHH.0000000000000276

12. Klepser M, Adams AJ, Srnis P, et al. U.S. Community Pharmacies as CLIA-Waived Facilities: Prevalence, Dispersion, and Impact of Access to Testing. Research in Social \& Administrative Pharmacy. 2015, doi: 10.1016/j.sagepharm.2015.09.006

13. U.S. Centers for Disease Control and Prevention (CDC). Waived Tests. Available from: https://www.cdc.gov/labquality/waived-tests.html (Accessed July 10, 2021)

14. Klepser ME, Adams AJ, Klepser DG. Antimicrobial stewardship in outpatient settings: Leveraging innovative physician-pharmacist collaborations to reduce antibiotic resistance. Health Secur. 2015, 166173, doi:10.1089/hs.2014.0083.

15. Adams AJ. Pharmacist Prescriptive Authority: Lessons from Idaho. Pharmacy. 2020;8:112. Doi: 10.3390/pharmacy8030112

16. Colorado Senate Bill 21-094. 2021. Available from: https://leg.colorado.gov/sites/default/files/2021a_09 4_signed.pdf (Accessed July 10, 2021)

17. Bacci JL, Coley KC, McGrath K, et al. Strategies to facilitate the implementation of collaborative practice agreements in chain community pharmacies. J Am Pharm Assoc. 2016;56(3):257-265.e2. DOI: http://dx.doi.org/10.1016/j.japh.2016.02.014 
18. Weaver KK. Collaborative practice agreements: Explaining the basics. Pharmacy Today. 2018;24(3):55. Available from: https://www.pharmacytoday.org/article/S10420991(18)30260-3/fulltext (Accessed July 10, 2021)

19. Adams AJ, Weaver KK. The Continuum of Pharmacist Prescriptive Authority. Ann Pharmacother. September 2016;50(9)778-84.

20. Cacciatore GG. The overregulation of pharmacy practice. Pharmacotherapy. 1997;17(2):395-396.

21. Adams, A.J. Transitioning Pharmacy to "Standard of Care" Regulation: Analyzing how Pharmacy Regulates Relative to Medicine and Nursing. Res. Soc. Adm. Pharm. 2018, 15, 1230-1235, doi:10.1016/j.sapharm.2018.10.008.

22. Adams AJ, Adams JL. Does Increased State Pharmacy Regulatory Burden Lead to Better Public Safety Outcomes? Innovations in Pharmacy. 2021;12(1):19. DOI: https://doi.org/10.24926/iip.v12i1.3598

23. Eid D, Osborne J, Borowicz B. Moving the Needle: A 50-State and District of Columbia Review of Laws Regarding Pharmacy Technician Vaccine Administration. Pharmacy 2019;7(4):168. https://doi.org/10.3390/pharmacy 7040168

24. Thierer A. Permissionless Innovation: The Continuing Case for Comprehensive Technological Freedom. March 15, 2016. Available from: https://www.mercatus.org/system/files/ThiererPermissionless-revised.pdf (Accessed June 10, 2021)

25. Moffett $P$, Moore G. The Standard of Care: Legal History and Definitions: the Bad and Good News. West J Emerg Med. 2011 Feb;12(1):109-112. 